\title{
"Indirect Regulation" of Environmental Hazards Through the Provision of Information to The Public: The Case of SARA, Title III
}

Richard C. Rich, W. David Conn, and William L. Owens

Title III of the Superfund Amendments and Reauthorization Act of 1986 seeks to reduce the risks of chemical accidents through a strategy of indirect regulation that relies on providing the public with information about chemical hazards. For this strategy to be effective, citizens must aggressively utilize the information provided to monitor industrial practices and press for risk reduction. Since prior research suggests it is very difficult to evoke the degree of citizen action that would be required to make a strategy of indirect regulation successful, and since the federal legislation provided no funds for implementation, there is a question of whether the structures set up by Title III are sufficient to achieve its objectives. This article reports the results of a national study that examined selected aspects of the implementation of Title III in an effort to assess the likely outcome of its attempt at indirect regulation. Our focus is on the degree to which the Title III-mandated Local Emergency Planning Committees are pursuing policies that are likely to get the necessary information to citizens and foster community debate on hazardous materials issues.

Each year billions of pounds of hazardous chemicals are released into the environment by tens of thousands of firms in the U.S. (Environmental Protection Agency, 1991). Many billions more pounds of these chemicals are manufactured, stored, and transported, posing both acute and chronic risks to human health and environmental quality (Goldman, 1991). How is government to respond to such a large and complex problem? What regulatory mechanisms are possible?

Title III of the Superfund Amendments and Reauthorization Act of 1986 (SARA), also known as The Emergency Planning and Community Right-to-Know Act, was an effort to address the issue of chemical hazards. Title III is a departure from traditional regulatory policy, offering an excellent example of an approach to regulation that is increasingly advocated for dealing with health and environmental issues. Passed in the aftermath of the devastating chemical accident in Bhopal, India, in 1984, SARA Title III was an effort both to encourage communities to prepare for chemical emergencies and to set in motion events that would lead to reductions in the risks of such incidents (Hadden, 1989; Musselman, 1989).

The first objective was pursued through the frequently used federal strategy of placing mandates on state governments and private industry. Every state was to create a system of Local Emergency Planning Committees (LEPCs) which were to identify potential sources of hazardous materials accidents in their communities and 
develop integrated plans for responding to emergencies. Industries handling hazardous materials were to report selected facts about their operations to the LEPCs in order to facilitate the development of emergency response plans. These plans were to be submitted to a Title III-mandated State Emergency Response Commission (SERC) for approval by October, 1988.

It was in pursuit of the goal of reducing chemical hazards that Title III was innovative. Rather than imposing specific demands for risk reduction measures on industry, Title III pursued an indirect strategy that relied on providing the public with information. Legislators apparently hoped that requiring firms to share data on their use of hazardous materials would both provide a vigilant public with the information it needed to monitor industry performance and cause industry to undertake voluntary risk-reduction efforts in order to reassure citizens and prevent both potential legal actions and political pressure for more formal regulation (Administrative Conference of the United States, 1989; Baram, Dillon, \& Ruffle, 1990). To this end, Title III requires that LEPCs receive from industry specified data on hazardous materials and provide that information to citizens on request. SARA also mandates a nationwide, computerized system of information on releases of hazardous materials which the public can access, known as the Toxics Release Inventory (TRI) (Goldman, 1992).

In addition, the LEPCs are charged with tasks which could contribute to an increased public awareness and encourage a community dialogue about environmental hazards (Hadden \& Bales, 1989; McNeil, Arkin, \& McCallum, 1989). First, the very composition of the local emergency planning committees encourages public discussion of chemical hazards. 'Title III requires that each committee include police, fire, civil defense, public health, hospital, and transportation officials, as well as representatives of facilities subject to Title III reporting requirements, citizens' groups, the media, and elected local officials. The LEPCs' primary role is to prepare and update integrated local emergency response plans for their communities. But they are also to involve the public in the planning process and to make available to the public information on the presence of hazardous materials in their communities and any release of these chemicals into the environment.

If the "regulation through information" strategy of Title III is to be effective in reducing chemical risks, the LEPCs must succeed in alerting the public to chemical hazards and in providing them with the information they need to hold industry and its public sector regulators accountable. In addition, the public must accept the challenge and aggressively utilize the information provided. However, prior research has found that it is very difficult to evoke the degree of citizen action that would be required to make indirect regulation of environmental hazards successful (Baram, Dillon, \& Ruffle, 1990; Pease, 1991). In addition, because federal legislation provided no funds for implementation of Title III, most LEPCs operate with highly limited budgets and staff support. This raises the question of whether the structures set up by Title III are sufficient to achieve its objectives.

This article reports the findings of a study that examined selected aspects of the implementation of Title III in an effort to assess the likely outcome of its strategy of indirect regulation. Our focus is on the degree to which the LEPCs are, in fact, pursuing policies that are likely to get needed information to citizens and thereby foster 
community debate on hazardous materials issues. Our analysis is based on data obtained from both a national survey of LEPCs and their members, and case studies of three communities, also on information derived from less systematic observation of many other state and local agencies charged with Title III responsibilities. It is important to note at the outset that Title III places very few explicit responsibilities for active risk communication on the LEPCs and that there are substantial differences of opinion among informed persons about how proactive the LEPCs should be in their efforts to inform the public about risks. Nothing we say here should be construed as a criticism of local LEPCs and their members, who for the most part are volunteers working with little or no budget or staff. This research is primarily an examination of the adequacy of an approach to achieving national policy objectives. Where there are shortcomings, it is often because that approach has left the LEPCs with insufficient resources or ambiguous directives.

\section{The Survey of LEPCs and Their Members}

Since Title III gives the Local Emergency Planning Committees a crucial role in providing the public with information on hazardous materials risks, we sought to learn how the committees defined their responsibilities and what actions they took to fulfill those responsibilities. The virtual impossibility of obtaining a complete and unbiased list of names and addresses of all LEPC members dictated against attempting to survey a random sample of the nation's LEPC members. Moreover, there is significant variation in the way individual states have organized their LEPCs in the absence of specific directions in the federal legislation (National Governors' Association, 1990). This made it important to sample in such a way as to allow meaningful comparisons of states. Consequently, we selected a sample of states judged to be typical (if not representative in a statistical sense) of the nation and attempted to survey all LEPCs in each of those states.

In choosing states for the sample, we sought to include: (a) one state from each of the EPA's 10 administrative regions to capture the effects of any variation in EPA regional practice with regard to Title III's provisions; (b) states likely to include LEPCs that were making concerted efforts to involve the public in the Tille III planning process or experimenting with creative approaches to risk communication, to give us a basis for comparing different approaches; (c) an overall balance among urban and rural areas and among areas with high and low concentrations of hazardous materialshandling facilities; and (d) examples of the range of ways in which states have been divided into LEPC jurisdictions. Application of these criteria led us to select the states of Alabama, California, Louisiana, Maryland, Missouri, New York, Rhode Island, Utah, Washington, and Wisconsin.

In January, 1989 (after the October, 1988, deadline for completion of local emergency response plans) we sent the chair of each of the 388 functioning LEPCs in these states a packet containing an LEPC Information Form requesting data on the committee itself, and a set of questionnaires for the individual committee members. A cover letter asked the chair to (a) complete the Information Form, (b) distribute the 
individual questionnaires to the members, and (c) collect the completed questionnaires, and mail all materials back to us. After dropping LEPCs that were "inactive" or that could not be contacted, the overall response rate for LEPCs as organizations was $56 \%$. There was, however, significant variation in response rate by state. For the sake of brevity, we will not discuss state-by-state results in this report. (Information on statelevel data can be found in Conn, Owens, and Rich, [1990].)

The committees that sent in Information Forms reported a total of 4,461 membership positions. We received 1,468 individual responses. This translates into an average individual response rate of $30 \%$ (though there was substantial variation among LEPCs). We judge this response to be adequate for two reasons. First, our observations indicate that most LEPCs depend primarily on the efforts of a core of active members and that many nominal members are only marginally involved in the committees. It is the active members who are most likely to understand the functioning of the LEPCs and to influence their operation. Since they are also most likely to be the ones attending a meeting at which the questionnaire was distributed and most likely to have the knowledge and interest to fill out a questionnaire, it may be that we have a far better sample of active members than of all members. Moreover, we may have a more accurate picture of the LEPCs from the responses of this active core than we would have gained from a larger sample of less involved members. Second, most of the patterns found in the responses we received are so strong that there is little reason to believe that having additional responses would have altered our basic conclusions.

Our data collection procedure may have allowed a disproportionate response from the more active, better organized local committees because their officers are more likely to be willing to take part in such a survey and to be able to contact their members and persuade them to participate. In addition, we probably got responses primarily from the more involved and concerned members of these committees since they are more likely both to have been at a meeting to receive the questionnaire and to be interested enough to complete it. We have no way of contacting nonresponders to determine if this bias actually exists in our data, but readers should be aware that our results may possibly be biased in favor of a positive picture of LEPC activities.

In an effort to discover what steps the LEPCs had taken to make hazardous materials information available to citizens, we asked LEPC chairs if their committee had taken each of a series of steps. Table 1 shows that, while most committees had put in place the basic structures necessary for making information available to the public, significant numbers had failed to take steps that could be vital to effective information sharing. For example, $41 \%$ had not actively advertised the existence or location of the office responsible for responding to citizens' requests for hazardous materials information. Without these efforts, there is little reason to expect citizens to know where to go with questions. Similarly, almost a third of all LEPCs did not provide citizens with assistance in interpreting hazardous materials information. Given the technical nature of this information, such assistance may be essential if citizens actually are to gain an understanding of the risks they face by examining Title III information. 


\section{Table 1}

\section{LEPC's Reported Efforts to Make Hazardous Materials Information Available to the Public}

\section{Activity}

Designated an office to disseminate information

Advertised the address and phone number of this office

Full-time employee given responsibility for office

Provide photocopying service at the office

Offer citizens assistance interpreting hazardous materials information

\section{\% of \\ LEPC's}

$92 \%$

$59 \%$

$77 \%$

$78 \%$

$67 \%$

Perhaps one reason that LEPCs might not make the sharing of Title III information a high priority is that they have received too few requests for such information to feel that the public is concerned with hazardous materials issues. In fact, $53 \%$ of LEPCs in our sample reported that they had received no requests, and $88 \%$ had received fewer than 10 inquiries. Only 5 organizations claimed to have received 50 or more requests. The average number of requests reported by all LEPCs was 4.5 . We can think of several reasons for the small number of requests: it may reflect a lack of public concern or insufficient time (since the passage of SARA) for people to know about the existence of LEPCs and the availability of Title III information. However, we believe that inadequate efforts by LEPCs to inform the public are a major factor. We note, for example, that there are weak but positive and statistically significant correlations between the number of requests received and whether the LEPC had (a) advertised the existence of an office to provide Title III information $(r=.16 ; p<.01) ;(b)$ invited the public to attend LEPC meetings $(r=.15 ; p<.02)$; and (c) sent representatives to address other organizations $(r=.13 ; p<.05)$.

We investigated the efforts of LEPCs to involve the public in developing or updating the local response plan by asking chairs to tell us how frequently their organization had used each of several possible techniques for gaining public input and informing the public of LEPC activities. Table 2 shows that more organizations report having used the first two methods of disseminating information-methods which place the burden of action on others-while fewer relied on the next three methods that require more outreach. We also asked if the LEPCs had developed a "press kit" to provide the local media with information for use in covering the Title III planning process and the most likely hazardous materials emergencies in their community. Only $4 \%$ said they had such a kit. 
Table 2

LEPC Efforts to Involve the Public in Response Planning

Activity
\% of LEPC's Doing It:

Frequently Never Frequencya

Invited the media to

cover LEPC activities

Placed announcements

of LEPC meetings

Invited public attendance at

LEPC meetings

Sent representatives to other

organizations

Held public hearings or

meetings on Title III

Published the response plan

for the public
$41 \%$

$43 \%$

$9 \%$

3.8

$3 \%$

$25 \%$

$24 \%$

2.9

$13 \%$

$26 \%$

2.8

$12 \%$

$35 \%$

2.4

$6 \%$

$46 \%$

2.1

Note: aOn a five-point scale in which 5 represents "frequently" and 1 represents "never."

Since their members' perceptions of the local committees' mission will profoundly influence what the LEPCs actually do about risk communication, we asked an open-ended question about what the members saw as the most important purpose of the LEPC after the response plan has been approved. Sixty-four percent gave an answer which had to do with maintaining the emergency response plan - updating it and coordinating it with other plans. Only $13 \%$ referred to educating the public about hazardous materials issues, while $10 \%$ said that providing the public with information about hazardous materials risks would be the LEPC's key purpose. The remaining members gave answers that fell into a wide range of other categories. This suggests that the members generally do not see the role of the LEPCs as shifting toward public education once the plan is in place. 
We also asked members to evaluate their committee's capacities in several areas, using a five-point scale. The responses summarized in Table 3 indicate that, as a group, members are highly confident of their organization's ability to handle planning tasks, but far less sure of its capacity for communicating with the public or environmental groups, and quite dissatisfied with the degree to which it has achieved public visibility or confidence. This pattern also appeared in members' assessment of the likelihood that their LEPC could accomplish each of several goals. Table 4 summarizes these answers by showing the percentage of members who said that the LEPC had a "better than 50/50 chance" of accomplishing the goal, and the average rating on a five-point scale in which " 5 " represented "very likely" and " 1 " corresponded to "not likely." While the majority were confident of their ability to achieve the more technical communication goals, minorities felt that the LEPC could effectively reach citizens or stimulate debate on environmental issues.

Table 3

Members' Evaluation of Their LEPC

\section{Characteristic}

Competent and dedicated members

Capacity for communicating with government

Capacity for communicating with business

Information gathering capacity

Capacity for analyzing information

Relations with news media

Communication with environmental groups

Communication with the public

Public confidence in ability to protect the community's interests

Public visibility
\% Rating Good

or Excellent

$78 \%$

$74 \%$

$67 \%$

3.8

$65 \%$

3.8

$62 \%$

3.7

$58 \%$

3.6

$44 \%$

3.4

$42 \%$

$32 \%$

$23 \%$

2.8

Note: "On a five-point scale in which 5 represents "excellent" and 1 represents "poor." 


\section{Table 4}

Members' Assessment of the Likelihood of Accomplishing Goals

Goal
Percent Saying

Better Than $\mathbf{5 0 / 5 0}$
Average

Rating ${ }^{\text {a }}$

Respond effectively to requests

for information

$76 \%$

4.0

Improve community understanding

of risk information

$52 \%$

Inform citizens of the plan's

provisions

$40 \%$

Secure adequate citizen input for

updating plan

$34 \%$

3.1

Stimulate discussion of

environmental issues

$33 \%$

3.1

Note: "On a five-point scale where 5 represents "very likely" and 1 represents "not likely."

Two groups that can help the LEPCs reach the public or that can create problems for the committees are local environmental organizations and the media. Accordingly, we sought to assess members' perceptions of the relationships between their LEPC and these groups. First, we asked them to rate the frequency of LEPC contacts with environmental groups on a five-point scale. Only $14 \%$ said that their committee had relatively frequent contact with such organizations, while $57 \%$ described contacts as relatively infrequent. In assessing the character of interactions with environmental groups, $35 \%$ of LEPC members described these contacts as closer to cooperation than confrontation, while $13 \%$ said that the contacts were more nearly confrontational than cooperative, and the majority rated contacts as neutral in character. While these responses indicate that it is uncommon for environmental groups and LEPCs to cooperate, there is some evidence that increased contacts between environmental groups and the LEPCs might produce better working relationships. In the first place, LEPC members who described contact as more frequent were more likely to describe those contacts as cooperative rather than confrontational $(r=.51 ; p<.0001)$, and those who saw contacts as more frequent were also more likely to say that they viewed local environmental activists as representative of the general public in their community $(r=.21 ; p<.0001)$. 
In an additional effort to assess LEPC members' perception of their organization's external relations, we asked them to rate the amount and quality of coverage that the LEPC receives from television, radio, and newspapers in their jurisdiction. As shown in Table 5, majorities rated all three types of coverage as insufficient and substantial percentages evaluated the quality of the coverage as less than adequate. If LEPC members were correct that their work does not receive the attention it deserves from the media, this could partially explain the low level of citizen interest in leaming about hazardous materials issues, suggested by the small number of requests for Title III information reported above.

\section{Table 5}

\section{Members' Views of Media Coverage of LEPC Affairs}

\section{Percent of Members Who:}

Rate Amount of Coverage

Type of Media

Newspaper

Radio

Television
As Less Than "Enough"a

$59 \%$

$67 \%$

$81 \%$
Rate Quality of Coverage As Less Than "Fair"b

$33 \%$

$45 \%$

Note: aBased on a five-point scale in which 1 represented "too little," 3 represented "enough," and 5 represented "too much."

bBased on a five-point scale in which 1 represented "poor," 3 represented "fair," and 5 represented "good."

The impression that LEPCs show little sign of moving to a more active role in risk communication is reinforced by members' responses to a question about how much time they devote to each of several tasks. Table 6 shows that members report giving significantly less time to outreach efforts (informing the public of hazardous materials issues and seeking public input) than to more narrowly focused planning and capacity-building activities. One explanation of this may be that LEPC members view outreach as primarily the responsibility of the committee chair. Examining the time allocation of chairs separately, however, reveals that while chairs report giving more time to all tasks than other members, they too devote significantly less time to outreach than to other functions.

This allocation of time stands in stark contrast to members' answers to our question about the value of public input in evaluating and updating the response plan. Forty-seven percent indicated that such input was "very important," while $43 \%$ rated it as "somewhat important," and only 9\% labeled it as "not very important." Perhaps members were only giving what they considered to be the "politically correct" answer 
Table 6

LEPC Members' Allocation of Time

Average Hours Per Month Allocated By:

Activity

Studying hazardous materials issues

Gathering information

Attending LEPC meetings

Hazmat response training

Evaluating information

Informing the public

Seeking public input for the

planning process
All Members ${ }^{a}$

4.9

2.7

2.5

2.0

2.8

1.7

3.4

0.7

0.9

0.6

1.1

Note: a Including the LEPC chairs.

to this question. It is also possible, however, that members do value citizen input but do not know how to go about securing it in practice. Interestingly, LEPC chairs were less likely than others to say that citizen input was valuable to the planning process. Only $38 \%$ rated it as "very important" while $48 \%$ said it was "somewhat important," and $14 \%$ said that citizen involvement was "not important". Given the crucial role of LEPC chairs in directing the committees' activities, their relatively low commitment to citizen participation may help explain why so little effort goes into seeking citizen input.

\section{Divisions Within the LEPCs}

SARA's Title III mandates that the LEPCs be drawn from several constituent groups in order to provide broad-based representation of the community on the committees, and in the hope of improving risk communication by ensuring that the committees have strong links to the community. How well have these goals been realized?

Responses to our survey indicate that $56 \%$ of committee members had a college degree and $32 \%$ had graduate education. Occupationally, 26\% were in fields that qualified them as emergency responders (law enforcement, fire protection, rescue squad), $24 \%$ were business managers or owners, $13 \%$ were public administrators, $2 \%$ 
were elected officials, $9 \%$ were in the health care field, and $3 \%$ worked in the media. This profile suggests that LEPC members are a diverse group in some respects but are not a cross section of the general public. They are far more likely than "the average citizen" to be well educated, professional, and affiliated with government and emergency response organizations.

We asked the members to tell us if they felt that they had been appointed to the local committee because of their affiliation with any of several groups. Table 7 summarizes their responses by reducing the groups to 5 categories. "Watchdog groups" include environmental groups, community organizations, and the media. Only $2 \%$ of our respondents saw their membership on the LEPC as a product of affiliation with an environmental group, while less than $4 \%$ saw themselves as representatives of the media and less than $4 \%$ identified with community organizations. The "independent" group, who did not feel that their appointment was associated with membership in any of the types of groups we listed, came primarily from business and government. Table 7 also shows that LEPC chairs were even less likely to feel that they were appointed because of their affiliation with a "watchdog" group, while almost half identified their affiliation with government as the source of their appointment.

In an effort to determine if the diversity in members' backgrounds results in different perspectives on issues before the LEPCs, we compared these five groups" responses to a variety of questions about the LEPC. This comparison (summarized in Table 8) revealed no consistent pattern of statistically significant differences among the groups' answers. Especially noteworthy is the fact that the "watchdog" group generally does not stand out from the other groups in its responses to any of the questions in our study. The one point on which watchdog members are statistically distinctive is in their view of the LEPC's relations with the media. On that subject, watchdog group members were more positive than the other groups.

\section{Table 7}

Group Affiliations of LEPC Members ${ }^{a}$

Group $\%$ of All Members

Emergency responders

Government officials

Business and industry

"Watchdog" groups

Independents
$29 \%$

$29 \%$

$21 \%$

$10 \%$

$12 \%$
\% of Chairs

Only

$16 \%$

$46 \%$

$16 \%$

$6 \%$

$14 \%$

Note: 'Based on members' assessment of the reason for their appointment. 
Table 8

Attitudes and Perceptions of Different Groups of LEPC Members

\section{\% of Group That: Responders Business Government Watchdog Independents}

Rates communication

with government as

excellent

$26 \%$

$23 \%$

$35 \%$

$32 \%$

$31 \%$

Rates communication

with public as excellent

$11 \%$

$7 \%$

$11 \%$

$10 \%$

$14 \%$

Rates communication

with environmental

groups as excellent

$10 \%$

$8 \%$

$10 \%$

$14 \%$

$16 \%$

Rates relations with

media as excellent

$22 \%$

$15 \%$

$25 \%$

$38 \%$

$17 \%$

Rates cooperation

with business as

excellent

$16 \%$

$25 \%$

$20 \%$

$18 \%$

$20 \%$

Sees contact with environmental groups as cooperative

$11 \%$

$10 \%$

$11 \%$

$13 \%$

$11 \%$

Sees LEPC's public

visibility as good

$21 \%$

$21 \%$

$21 \%$

$25 \%$

$28 \%$

Sees public confidence

in LEPC as good

$31 \%$

$26 \%$

$31 \%$

$22 \%$

$36 \%$

Rates citizen input to

planning as important

$52 \%$

$38 \%$

$44 \%$

$49 \%$

$55 \%$

Describes local environmental concerns as high

$32 \%$

$33 \%$

$40 \%$

$37 \%$

$34 \%$

Sees local environ-

mentalists as representative

of the public

$46 \%$

$41 \%$

$53 \%$

$51 \%$

$45 \%$ 
This high level of agreement among LEPC members could be viewed as a sign of effective groups who share a consensus on most issues. However, it also could reflect a flawed selection process in which only those members of watchdog groups who will not "make waves" are recruited for the LEPCs. Selecting watchdog members by this criterion might facilitate assembling the emergency response plans on time, but having less critical watchdog members may prevent the LEPC from encouraging public debate of environmental risks.

\section{Case Studies}

In an effort to understand the dynamics behind the national survey results, we conducted case studies in three communities in which exceptional efforts were being made to reach the public with information on hazardous materials risks. We sought out these atypical cases in order to discover which communication strategies might be effective and to provide a test of what could realistically be expected of the system set up under Title III. To select the cases we spoke with EPA regional and state environmental officials, as well as representatives of environmental and citizens' groups from across the nation. While our sources could identify very few valid examples of active risk communication programs anywhere in the country, we were able to confirm suitable case studies in three very different areas. These were (a) a heavily industrialized rural area of 25,000 people in a Southern state, (b) a mid-size city and surrounding county of just under 400,000 people in a Rocky Mountain state, and (c) an urbanized West Coast county with a population of approximately 750,000.

We visited each of the case study communities and met with LEPC members, emergency response officers, public officials, media figures, and others who were in a position to be familiar with environmental issues in the community. Through a total of 30 in-depth interviews we obtained (a) detailed information regarding the risk communication programs, (b) insights from the risk communicators based on their experiences, and (c) information from which to identify a sample of opinion mediators in each community for a follow-up mail survey.

These case studies were not designed to assess the adequacy of the individual risk communication activities carried out in each of the communities. Rather, they allow an overall assessment of the capacity of the LEPCs for effective risk communication.

The activities we observed were carried out by LEPCs in cooperation with public agencies, citizen groups, and industry. This cooperation is quite common because LEPCs seldom have an operating budget or paid staff and must often rely on other organizations to finance and/or assist with the execution of any public outreach efforts. These projects represented a significant investment of effort for the organizations involved. Our observations, however, indicated that they fell far short of what would be necessary (in our opinion) to raise public awareness levels enough to create a system of "indirect regulation."

In the first place, very little of what we saw in the case studies qualifies as true risk communication. The information communicated tended to focus on matters such 
as the existence of the emergency response plan, and what to do in an emergency. Topics such as the nature of the risks facing the community and the probability of harm commonly were not addressed. Given that we chose to examine communities where special communication efforts were being made, we may reasonably assume that even less risk communication is being undertaken in most other communities.

Second, LEPC members are not public relations or communications experts and, as a result, had overlooked significant flaws in their communications efforts. Examples include the following. Publications often were not designed so as to capture citizens' attention or communicate technical information effectively. Material placed in public libraries was very difficult to locate because it was notcross-referenced under terms that lay persons are likely to know to use (like "pollution" or "chemicals") and, once found, this information generally was not in a form that citizens could understand. Citizens who had attended public forums on hazardous materials issues said they involved primarily the one-way provision of technical information beyond the comprehension of most audiences, and did not encourage dialogue. Local media figures tended to feel that most LEPC activities were not "newsworthy" and that they had not been recruited as allies in the effort to educate the public.

The surveys of opinion mediators in these three communities provide an indicator of the impact of the LEPCs' risk communication efforts. The purpose of this survey was to gather information on issues such as the amount of public concern over hazardous materials, the level of popular awareness of emergency response plans, and the sources that citizens relied on for information on hazardous materials. The sample was composed of a group of persons who might reasonably be expected to serve as opinion mediators in their communities. It included local political officeholders and leaders of civic groups, neighborhood organizations, environmental groups, parentteacher associations, health organizations, and the business community. These people could play a vital role in distributing hazardous materials information to the community through their organizational contacts.

We received responses from 104 of the 221 individuals to whom questionnaires were mailed, for an overall response rate of $47 \%$. While this number of respondents is low, there are several reasons to think the results are valuable. In response to most of the questions there are very strong patterns that are consistent with the information we obtained while in the communities. Moreover, with the exception of questions about the level of public concern over hazardous materials in the individual communities, the responses in all three localities were highly similar. Because of this latter fact, we will present the responses from all three communities as a single group.

Only $28 \%$ of the respondents said they feel personally well-informed about what types of hazardous materials emergencies are most likely to occur in their community, and only $11 \%$ said that they knew what to do to protect themselves and their families in the event of a major hazardous materials emergency. While $64 \%$ said they knew that citizens have a legally established right to information about hazardous materials in their community, only $30 \%$ were aware that an organization in their community had conducted a hazards analysis and had developed an emergency response plan. When asked to identify the organization which developed the plan, most 
of the respondents who claimed to know about its existence mentioned a government agency such as the fire or emergency services department. The LEPC was mentioned by name only twice in all the responses.

Given the makeup of the group to which the questionnaire was sent, it is reasonable to expect that the general public in these communities is even less familiar with these issues. Such an assumption is consistent with the respondents' perception of the public's awareness of the emergency response plan. When asked to rate public awareness on a scale in which " 1 " represented "not aware" and " 5 " stood for "highly aware," one-third of respondents chose a rating of " 1 " and a majority rated public awareness as a " 1 " or " 2 ."

There is no indication that the respondents knew how to learn more about hazardous materials issues through any mechanism associated with TitleIII. Only 16\% claim to have seen an explanation of the process by which citizens can learn about hazardous materials risks under Title III's community right-to-know provisions. When asked an open-ended question about where they would turn for information about hazardous materials handled by a given firm in their community, respondents most frequently mentioned a local public agency such as the health, fire, or police department. Only four people mentioned the LEPC by name. It is worth noting, however, that $76 \%$ of our opinion mediators said they would spend two hours studying the hazards analysis and emergency response plan for their community, if it were available; $71 \%$ said they would attend a two-hour public meeting to address these issues; and $81 \%$ said they would spend 30 minutes a week reading news articles or other materials to keep up-to-date on these issues. While these responses may be overly optimistic, they suggest that attentive citizens may be willing to invest time in increasing their understanding of hazardous materials risks if given the opportunity.

\section{Conclusions and Recommendations}

The results of this study strongly suggest that the arrangements made for implementation of SARA Title III are insufficient to make the "regulation-throughinformation" strategy fully effective. Our confidence in the accuracy of these findings is enhanced by the fact that they are consistent with those reported in other studies of LEPCs. (For examples, see Lindell \& Meier, 1991; Lynn, 1989; Pease, 1991; and Sutton, 1989.) Furthermore, although our study was conducted in the early stages of Title III implementation, we believe that our findings still apply. This belief is based in part on information obtained through informal contacts (e.g., Kartez, 1992).

A great deal of effort has gone into gathering information on hazards and developing emergency response plans. However, we have seen no evidence to suggest that public awareness of hazardous materials issues is being raised to the degree needed to make the assumptions of indirect regulation operative. Most Local Emergency Planning Committees in our study have focused on the technical aspects of their job and have not made a concerted effort to bring hazardous materials issues to public attention. This is quite understandable given the constraints under which they labor. They generally run entirely on volunteer effort and have little or no independent budget 
or staff. Their mission has been defined primarily in terms of developing a technically adequate emergency response plan. As a result, they have few members with extensive backgrounds in public relations, citizen participation, or communications. Most make risk communication a low priority and do not know how to go about obtaining public involvement even when it occurs to them to attempt to do so. Moreover, most have been given very little direction from the state or federal government concerning their role in nonemergency risk communication, so that responsibility for this important function is seldom clearly assigned at the local level.

As presently structured, LEPCs cannot be expected to serve as a catalyst for active public monitoring of local environmental risks. They lack notonly the resources necessary for such an effort, but also the political motivation. Given the selection processes that are commonly used, LEPC members are likely to regard local government or industry as their main constituency. While ensuring public safety is accepted as their primary mission, most LEPCs have little contact with the public or even with community organizations that could introduce a citizens' perspective. The persons to whom they feel most immediately accountable are most often their private sector employers or their public sector supervisors. Moreover, many key members come from emergency response backgrounds that stress one-way communications with the public (in order to ensure compliance with emergency instructions) and make little room for questioning or critical analysis of options. Under these conditions, it is unrealistic to expect LEPCs to attempt to foster public debate of environmental issues or to focus on hazard reduction rather than emergency response.

Since the current budget climate militates against any large infusion of funds into risk communication efforts, the question becomes: What strategies might make the LEPCs more effective risk communicators and what tactics might they use to raise public awareness within the constraints of existing policy and institutions? We need to go beyond the specific findings of this study to draw on more general observations and our larger understanding of the dynamics of hazardous materials risk communication to answer this question. Accordingly, the recommendations that follow cannot be defended by specific data in all cases. Even so, we feel that they will stand up to the test of implementation.

It is important to recognize that the formal requirements of Title III regarding the provision of hazardous materials information to the public can be fulfilled in a largely passive fashion. As a result, even though the spirit of the law may require more, local policymakers with limited resources typically will want to know what benefits they can expect from a hazardous materials risk communication effort. The first task, then, is for state and federal agencies vigorously to promote the idea that there are highly practical reasons why communities should have a proactive risk communication program. We have discussed these reasons in other work (Conn, Owens, \& Rich, 1990). They relate to both the practical effectiveness of emergency response plans and the political wisdom of informing citizens of dangers in advance of any foreseeable accident.

Perhaps the key factor that could facilitate effective risk communication is the LEPCs' development of a clear concept of their role in such an effort. We argue that they should be encouraged by the EPA and state agencies to adopt the role of planning for and advocating active risk communication by other organizations. It is as unrealistic 
to expect them actually to carry out significant risk communication efforts as it would be to ask them to conduct actual emergency response activities (such as fire fighting). They should play to their strength as planning organizations and develop a comprehensive plan for pre-emergency and emergency risk communication in their communities. This plan should be made a formal part of the emergency response plan, and responsibility for its implementation should be given to agencies with the resources to do the job. Indeed, in those communities that have engaged in risk communication efforts associated with the LEPCs, the actual work on and financial support for the programs have been provided by a local government agency, or by an industry or citizen group, working in collaboration with the LEPC.

Even if the LEPCs' role is limited to planning risk communication programs, their membership should be diversified to include more media representatives ${ }^{1}$ and more members with skills in community participation. These latter might include members of community and environmental groups as well as public officials with the requisite skills. In order to encourage the development of strong working relationships between the LEPCs and community groups, we would argue that existing regulations concerningLEPC composition should be amended formally to require that at least onefourth of the membership be drawn from local environmental and community groups. To open the membership more generally, there should also be public announcement of the appointment of persons to the LEPC and provisions for the public to nominate individuals to serve.

Finally, it is important to recognize the complexity and difficulty of communicating risk information in a pre-emergency situation. There is apparently a good deal of natural resistance among the public to learning about such threats and very little theory on which to base effective communications efforts (Handmer \& PenningRowsell, 1990). Accordingly, it is unreasonable to expect LEPC members to be able to plan a risk communications program without significant assistance. We recommend three lines of attack. First, the Environmental Protection Agency, the Department of Energy, the Federal Emergency Management Agency, and other concerned federal agencies should step up their efforts to encourage and support LEPCs in planning and executing pre-emergency risk communication programs. Since the federal agencies themselves currently do not have all the knowledge they need to advise others on mounting effective programs, this will require the further development and validation (e.g., by field testing) of techniques for informing the public about risks and involving them in decisions about risk reduction and emergency response. Second, all agencies should encourage the sharing of information on techniques of this kind. For example, areas with nuclear power plants and areas accustomed to natural disasters such as hurricanes, floods, or earthquakes, may already have in place significant programs to inform the public about the nature of these risks and the proper course of action in an emergency. It may be possible for the LEPCs to learn from their experience, to share channels of communication, and/or to draw on some of the same resources in arranging information campaigns. State and federal agencies should establish institutional frameworks to facilitate these exchanges. Finally, while it may be unwise to attempt to bring risk communication specialists onto the LEPCs as full-time members, most committees could benefit from the services of a communications advisory committee to assist in developing a risk communication plan and reviewing specific projects. 
Each LEPC should be encouraged to tap into the media, advertising, health, and academic communities in their area to recruit such an advisory group.

Our observations revealed that few LEPCs are aware of what other organizations are doing in the risk communication area ${ }^{2}$ However, State Emergency Response Commissions (SERCs) can play an important role in solving this problem because they are well situated to gather information on risk communication efforts and to share this information with LEPCs. We therefore recommend that SERCs become clearing houses for such information and make concerted efforts to bring LEPC members together periodically to discuss risk communication and to participate in workshops on involving and informing the public.

The overall objective of these changes is not only to increase the capacity of the LEPCs to fulfill their risk communication role, but, more importantly, to make the LEPCs genuine community organizations that can serve as mechanisms through which the public can help make decisions about how to respond to the chemical risks that exist in their community.

$$
\text { *k * * }
$$

Richard C. Rich is an associate professor of political science and a faculty associate with the University Center for Environmental and Hazardous Materials Studies at Virginia Polytechnic Institute and State University.

W. David Conn is a professor and Head of Environmental Design and Planning at Virginia Polytechnic Institute and State University. He is also Associate Director of the University Center for Environmental and Hazardous Materials Studies.

William L. Owens is a research Associate with the Toxic Substances Research and Teaching Program at the University of California at Davis.

\section{Notes}

'We recognize that there are potential conflicts of interest to be resolved before the media members can be fully effective. See Burkhart (1990) for a discussion.

${ }^{2}$ We are trying to address this problem ourselves through the publication of Hazardous Materials Dialogue.

\section{References}

Administrative Conference of the United States. (1989) Risk communication as a regulatory alternative for protecting health, safety and environment. Washington, DC: Author.

Baram, M. S., Dillon P. S., \& Ruffle, B. (1990). Managing chemical risks: Corporate response to SARA Title III. Medford, MA: Tufts University, The Center for Environmental Management.

Burkhart, F. N. (1990). Journalists as bureaucrats? Perceptions of media roles in local emergency planning. Paper presented at the Annual Meeting of the Society for Risk Analysis, New Orleans, LA.

Conn, D. W., Owens, W. L., \& Rich, R. C. (1990). Communicating with the public about hazardous materials: An examination of local practice (EPA report No. 230-04-90-077). Washington, DC: U.S. Environmental Protection Agency.

Environmental Health Center (1989). Chemicals, the press and the public: A journalist's guide to reporting on chemicals in the community. Washington, DC: National Safety Council. 
Environmental Protection Agency. (1991). Toxics in the community: National and local perspectives (EPA report No. 560/4-91-014). Washington, DC: Author.

Goldman, B. A. (1991). The truth about where you live. New York: Random House.

Goldman, B. A. (1992). Community right to know: Environmental information for citizen participation. Environmental Impact Assessment Review, 12, (3), 315-325.

Hadden, S. G. (1989). A citizen's right to know: Risk communication and public policy. Boulder, CO: Westview Press.

Hadden, S. G., \& Bales, B.V. (1989). Riskcommunication about chemicals in your community: A manual for local officials (EPA report No. 230-09-89-066). Washington, DC: U.S. Environmental Protection Agency and Federal Emergency Management Agency.

Hance, B. J., Chess, C., \& Sandman, P. (no date). Improving dialogue with communities: A risk communication manual for government. New Bunswick, NJ: New Jersey Department of Environmental Protection.

Handmer, J., \& Penning-Rowsell, E. (Eds.). (1990). Hazards and the communication of risk. Aldershot, England: Gower Publishing Co.

Kartez, J. (1992). [Evolving roles of LEPCs in hazard management]. Unpublished raw data.

Lindell, M. K., \& Meier, M. J. (1991). Effectiveness of community planning for toxic chemical emergencies. Lansing, MI: Michigan Department of Natural Resources, Environmental Response Division.

Lynn, F. M. (1989). Citizen involvement in using community right-to-know information for emergency planning and source reduction. Paper presented at the Annual Meeting of the Air and Waste Management Association, Los Angeles, CA.

McNeil, C., Arkin, E. B., \& McCallum, D. B. (1989). Toxic and hazardous substances, Title III and communities: An outreach manual for community groups (EPA report No. 56-1-89-002). Washington, DC: U.S. Environmental Protection Agency, Office of Toxic Substances.

McCallum, D. B., Hammond, S. L., Morris, L. A., \& Covello, V. T. (1990). Public knowledge and perceptions of chemical risks in six communities: Analysis of a baseline survey (EPA report. No. 230-01-90-074). Washington, DC: U.S. Environmental Protection Agency.

Musselman, V. C. (1989). Emergency planning and community right-to-know: An implementer's guide to SARA Title III. New York: Van Nostrand Reinhold.

National Governors' Association (1990). The emergency planning and community right-to-know act: A status of state actions. Washington, DC: National Govemors' Association.

National Research Council. (1989). Improving risk communication. Washington, DC: National Academy Press.

New Jersey Department of Environmental Protection, Division of Science and Research (no date). Improving dialogue with communities; A risk communication manual for government.

Pease, W. S. (1991). Responses to information about chemical hazards: Evaluating the efficacy of right to know programs in California. Paper presented at the Meeting on Interdisciplinary Approaches to the Study of Economic Problems, Stockholm, Sweden.

Sutton, V. V. (1989). Perceptions of local emergency planning committee members ' responsibility for risk communication and a proposed model risk communication program for local emergency planning committees under SARA Title III. Unpublished Dissertation, University of Texas at Dallas. 